\title{
Políticas públicas para formação de professores: Pibid, mestrados profissionais e PNEM
}

Marinalva Vieira Barbosa

Natália A. Morato Fernandes

\section{Resumo}

O objetivo deste artigo é analisar as concepções, o perfil docente, os diálogos e as contradições que orientam as políticas formativas atuais, com base nos documentos de criação do Programa Institucional de Bolsa de Iniciação à Docência (Pibid), dos mestrados profissionais (MPs) e do Pacto Nacional pelo Fortalecimento do Ensino Médio (PNEM). Especificamente, interessa saber qual perfil docente tais políticas buscam construir e se mantêm relação entre si e entre as metas e objetivos do Plano Nacional de Educação (PNE 2014-2024).

Palavras-chave: políticas; formação; docência; concepções. 


\section{Abstract \\ Public policies for teacher training: Pibid, professional master's degree and PNEM}

This article aims to analyze the conceptions, the teacher profile, the dialogues and the contradictions that guide the current formative policies; based on the documents which created the Programa Institucional de Bolsa de Iniciação à Docência (Pibid), professional master's degrees and the Pacto Nacional pelo Fortalecimento do Ensino Médio (PNEM). Specifically, it is interesting to uncover what teacher's profile these policies seek to build and whether they are related to each other and to the goals of the Plano Nacional de Educação (PNE 2015-2024).

Keywords: policies; education; teaching; conceptions.

\section{Introdução}

As políticas públicas para formação inicial e continuada de professores, dentro do escopo de preocupações relacionadas à melhoria da educação, no Brasil das últimas décadas, ganharam relevância nas pesquisas acadêmicas e também nos investimentos realizados pelos governos das esferas municipal, estadual e federal com vistas à melhoria da educação básica. Na mesma direção, houve investimento considerável em busca da melhoria da formação de professores, entretanto, esse tema continua presente nos debates em razão dos problemas que apresenta. A formação de professores é não só uma demanda não esgotada, mas também segue como um grande desafio, principalmente quando se focalizam os avanços ou não das políticas públicas implantadas (Azevedo; Aguiar, 2001; Gatti, 2008; Gatti; Barretto; André, 2011; Montandon, 2012).

Diante dessa atualidade, considerando os objetivos formativos presentes nos documentos legais de criação (portarias, decretos e documentos de apresentação) do Programa Institucional de Bolsa de Iniciação à Docência (Pibid), Programas de mestrados profissionais (MPs) e Pacto Nacional pelo Fortalecimento do Ensino Médio (PNEM), procuramos responder a três perguntas:

1) Como a formação inicial e continuada são concebidas? Especificamente, qual perfil do profissional é delineado nos objetivos desses programas?

2) Há diálogo entre os objetivos desses programas no que diz respeito à formação?

3) A formação proposta pelos três programas dialoga com o que as metas do Plano Nacional de Educação (PNE 2014-2024) estabelecem?

A escolha desses três programas para análise se justifica pelo seguinte:

a) são de abrangência nacional, portanto alcançam professores de todas as regiões do Brasil; 
b) alcançam professores de todos os níveis da educação básica, principalmente a partir do ensino fundamental;

c) possibilitam, entre a formação inicial e continuada que oferecem, uma espécie de continum, uma vez que o bolsista do Pibid pode vir a ser o aluno dos mestrados profissionais e/ou poderá estar entre aqueles que atuam no ensino médio, que são também público da formação oferecida pelo PNEM.

No que diz respeito à estrutura deste artigo, inicialmente apresentamos uma breve discussão sobre a formação de professores no Brasil, enfocando as políticas, as contradições e as influências que a organização das políticas para formação sofre em razão das demandas sociais e econômicas. Nas análises, após um resumo de apresentação de cada programa, o foco recai sobre as concepções presentes nos seus respectivos objetivos e, consequentemente, sobre o professor que cada um visa formar. A título de conclusão, buscamos delinear os diálogos entre as propostas desses programas, suas contradições e de que maneira eles contribuem para a efetivação das metas 15, 16, 17 e 18 do PNE 2014-2024.

\section{Formação de professores no Brasil: políticas, contradições e influências}

Regulamentação e política governamental

No quadro das transformações sociais, políticas e econômicas das últimas décadas, especificamente nos anos seguintes ao processo de redemocratização do Brasil, a formação de professores ganhou destaque no âmbito das políticas educacionais, como consequência dos debates que ganharam força sobre a qualidade do ensino oferecido na escola básica. Ou seja, como tais discussões vêm ocorrendo também em contexto de importantes demandas por uma educação básica que atenda às exigências econômicas relacionadas à mão de obra qualificada para o mercado de trabalho contemporâneo, por isso, a escola passou a ser vista como a responsável por criar as condições para que os indivíduos pudessem desenvolver suas capacidades e aprender os conteúdos necessários para compreender e para participar das relações sociais, econômicas e culturais cada vez mais plurais.

A qualidade da educação e a formação de professores passaram a ser pauta nas agendas e discussões sobre educação no Brasil e nas ações e políticas propostas pelo Ministério da Educação (MEC). Passaram a ser faces de uma mesma questão e, consequentemente, esta última ganhou ressonância no processo de elaboração e aprovação da Lei de Diretrizes e Bases da Educação Nacional (LDB - Lei no 9.394/1996). Naquele momento, a meta era fazer com que, em dez anos, todos os professores que atuavam na educação básica, nos seus diferentes níveis, alcançassem a formação superior. Não tendo sido alcançada essa meta, o parágrafo $4^{\circ}$ do art. 87, foi revogado. 
Diante disso, a formação de professores tornou-se um tema crucial, implicado em qualquer discussão que visasse propor políticas públicas para a educação escolar, devido ao reconhecimento de que os desafios apresentados para a escola contemporânea exigiam/exigem um patamar cada vez mais elevado de formação do seu corpo docente. Tal preocupação está registrada no art. 61 da LDB, que define a formação dos profissionais da educação como resposta às necessidades e objetivos dos diferentes níveis de ensino e às características de cada fase de desenvolvimento do educando. No artigo seguinte, define-se que a formação mínima do professor da educação básica deverá ser realizada em nível superior, em instituições de ensino superior (IES):

Art. 62. A formação de docentes para atuar na educação básica far-se-á em nível superior, em curso de licenciatura plena, admitida, como formação mínima para o exercício do magistério na educação infantil e nos cinco primeiros anos do ensino fundamental, a oferecida em nível médio, na modalidade normal. (Redação dada pela lei $n^{\circ}$ 13.415/2017).

$\S 5^{\circ}$ A União, o Distrito Federal, os Estados e os Municípios incentivarão a formação de profissionais do magistério para atuar na educação básica pública mediante programa institucional de bolsa de iniciação à docência a estudantes matriculados em cursos de licenciatura, de graduação plena, nas instituições de educação superior. (Incluído pela Lei no 12.796/2013). (Brasil, 1996).

No decorrer dos anos 2000, ocorreu a expansão da oferta de programas e projetos de formação (Brasil. Capes, 2013). A parceria entre universidade e escola foi intensificada. Consequentemente, a qualidade dessa formação e a sua efetivação em transformações das práticas de ensino e aprendizagem também passaram a ser um tema de grandes preocupações, uma vez que, na ponta desse processo, estão as exigências sociais e econômicas mais amplas de produção de um indivíduo capaz de compreender, agir e propor mudanças no contexto global e neoliberal em que está inserido (Mazzeu, 2009; Tommasi; Warde; Haddad, 2009).

O MEC, de acordo com Weber (2015), ao longo dos anos que precederam a aprovação da LDB, mostrou-se bastante proativo na execução da tarefa de oferecer meios para impulsionar a efetivação de ações de formação inicial e continuada de professores. Dentre elas, a mais expressiva, segundo a autora, foi a instituição da Política Nacional de Formação de Profissionais de Magistério da Educação Básica, que ficou sob a Coordenação de Aperfeiçoamento de Pessoal de Nível Superior (Capes), especificamente na Diretoria de Formação de Professores da Educação Básica. Essa política, no momento da sua instituição, em 2009, fundamentalmente, visou firmar o reconhecimento da importância do professor na realização do processo educativo escolar e, em consequência disso, a necessidade de sua valorização profissional.

Entretanto, todas essas mudanças, efetivadas à luz do texto da LDB e em documentos oficiais que a desdobraram, não foram suficientes para produzir a formação requerida para os profissionais da educação básica, de maneira a atender às necessidades atuais da escola básica, principalmente no que diz respeito ao que dela é demandado. Os investimentos feitos também não resultaram no número de profissionais necessários para ocupar a demanda da escola básica. Ainda é muito 
comum associar o desempenho dos alunos da educação básica em exames nacionais e internacionais à qualidade de formação do professor. Nos textos críticos ao ensino realizado pela escola básica, os objetos criticados são muitas vezes os mesmos de décadas anteriores a todo esse movimento em busca da melhoria da educação pela via do investimento na formação inicial e continuada.

Consequentemente, nas metas 15, 16, 17 e 18 do PNE 2014-2024, questões como formação específica, formação em nível de pós-graduação, valorização profissional e plano de carreira compõem o eixo central intitulado "Valorização dos Profissionais da Educação: formação, remuneração, carreira e condições de trabalho".

O objetivo da nota técnica da Meta 15 é, na vigência do PNE, garantir a formação específica do professor. Essa nota trata de um problema antigo, bastante presente nas discussões sobre as políticas de formação, qual seja: o desvio de função. Segundo o texto da nota, no Brasil de 2013, devido à escassez de licenciados para determinadas áreas, ainda era comum professores atuarem em disciplinas para as quais não foram formados. O percentual de professores com formação compatível com a disciplina que lecionava era de $50 \%$ e, com pequenas variações, esse percentual era similar para todos os níveis de escolarização: educação infantil, ensino fundamental e médio.

Na conclusão dos resultados apresentados na nota técnica da Meta 15, afirma-se que é necessário ampliar os esforços e investimentos na formação superior nas áreas específicas em que atuam muitos professores da educação básica. Nesse sentido, a Meta 16 já aponta um direcionamento desse investimento, qual seja: a formação em nível de pós-graduação de 50\% dos professores hoje ativos e também a oferta de formação continuada em suas áreas de atuação.

A "escassez oculta" ou a falta de profissionais com formação adequada à área em que atuam, de fato, põe em evidência dois problemas: a desvalorização da carreira docente e a falta de um plano de carreira que contemple também as questões relacionadas à remuneração. As metas 17 e 18 voltam-se para a valorização dos profissionais da educação básica, prevendo inclusive a equiparação salarial com as demais profissões com o mesmo nível de formação, e para o estabelecimento de planos de carreiras baseados no piso salarial previsto na Constituição Federal. Em síntese, tais metas do PNE representam o reconhecimento de que ainda são necessárias políticas governamentais que visem criar condições efetivas para que esse profissional se sinta valorizado socialmente pelo esforço que precisa depreender na formação das gerações futuras, na perspectiva do que lhe é demandado pela sociedade contemporânea (Gatti; Barretto; André, 2011).

\title{
Pibid, MPs e PNEM: abrangências e concepções
}

\author{
Contextualização e eixos de sustentação
}

Os programas analisados neste artigo foram criados com vistas a alcançar professores que atuam em diferentes níveis do magistério da educação básica, 
enfocando a formação inicial e continuada. Criados em diferentes momentos da implantação e execução da Política Nacional para Formação de Profissionais do Magistério da Educação Básica, têm como eixo comum e orientador a "equalização de oportunidades educacionais e padrão mínimo de qualidade do ensino" (Brasil, 2008). Esse eixo sintetiza as atribuições da União, conforme previsto no parágrafo $1^{\circ}$, do art. 211, da Constituição Federal e que embasou o Decreto no 8.752/2016 (que retoma o Decreto no 6.755/2009). Esse decreto instituiu a Política Nacional de Formação de Profissionais do Magistério da Educação Básica, cujos objetivos, conforme o art. $4^{\circ}$, estavam previstos para ser efetivados a partir da "criação dos Fóruns Estaduais Permanentes de Apoio à Formação Docente, em regime de colaboração entre a União, os Estados, o Distrito Federal e os Municípios, e por meio de ações e programas específicos do Ministério da Educação" (Brasil, 2009).

No contexto dessas regulamentações, o Pibid, criado em 2007 por meio da Portaria Normativa MEC n 38/2007, e, instituído no âmbito da Capes, pela Portaria Normativa Capes n 122/2009, teve dois objetivos:

a) incentivar a iniciação à docência durante a formação inicial de professores nos cursos de licenciatura de instituições públicas de ensino superior, valorizando o magistério e aqueles que optaram pela carreira docente;

b) elevar a qualidade das ações que, nessas instituições, estavam voltadas para a formação inicial de professores.

Consequentemente, para a execução desses objetivos primeiros, estão previstos outros que alcançam a escola ao estimularem a integração da educação superior com a educação básica por meio da parceria entre secretarias estaduais e municipais de educação e universidades públicas, num trabalho colaborativo com vistas à melhoria do ensino nas escolas públicas - consideradas também como parceiras, corresponsáveis pela formação dos futuros professores.

Na modalidade mestrados profissionais (MPs), foram criados alguns programas voltados para a formação de professores da educação básica pública. Os MPs ganharam força na empolgação e ebulição que programas como o Pibid geraram nas universidades federais. Assim, o MEC, por meio da Portaria no 17/2009, que retoma a Portaria Normativa MEC n 07/2009, definiu os MPs como cursos de pós-graduação stricto sensu com foco na prática profissional e que, por isso, deveriam habilitar o profissional concluinte a:

a) a atuar em atividades técnico-científicas e de inovação, por meio da incorporação do método científico;

b) possuir uma formação apropriada que o permita aplicar o conhecimento adquirido durante a formação com rigor metodológico;

c) incorporar (mantendo-se atualizado) os avanços científicos e tecnológicos de forma a construir solução para problemas específicos no seu ambiente de trabalho. 
Com o mesmo intuito de oferecer formação continuada para professores em atuação na educação básica, o MEC, também por meio da pactuação entre universidades, estados e municípios e demais entidades engajadas em questões educativas, criou - por meio da Portaria no 1.140/2013 - e implementou, em 2014, o Pacto Nacional pelo Fortalecimento do Ensino Médio (PNEM), cujos objetivos e ações foram organizados em torno dos seguintes eixos:

a) garantir a formação de professores e demais profissionais da escola;

b) ampliar os espaços de formação dos profissionais que atuam nessa etapa de ensino;

c) induzir ao redesenho curricular do ensino médio;

d) disponibilizar recursos pedagógicos e novas tecnologias.

Esses objetivos estão em consonância com a LDB e com as atuais Diretrizes Curriculares Nacionais do Ensino Médio (DCNEM), definidas na Resolução CNE/CEB n 2/2012.

Em síntese, o Pibid alcança a formação inicial de professores em todos os níveis de escolarização - da educação infantil ao ensino médio. Os MPs, nas áreas em que foram instituídos, oferecem formação continuada a professores de diferentes níveis da educação básica - do ensino fundamental ao médio. Por sua vez, o PNEM alcança o professor do ensino médio, portanto, dos últimos anos da educação básica. Nesse sentido, o público do Pibid tem a possibilidade de se fazer presente nos demais programas, sendo que o público dos MP's certamente pode ser o público do PNEM. Aliás, a possibilidade de relação entre os públicos desses programas está assinalada no Regulamento do Pibid (Portaria $n^{\circ}$ 46/2016, anexo I, art. $7^{\circ}$, inciso II), em que a Capes coloca como uma das características necessárias aos projetos institucionais a articulação, nas propostas das IES, do Pibid com os programas institucionais do MEC e, dentre os enumerados, está o PNEM. Trata-se, portanto, de um conjunto de programas que alcança o professor da educação básica nos seus diferentes momentos e/ou níveis de formação e atuação e, consequentemente, oferecem subsídios para a construção da concepção do que seja o fazer docente nos dias atuais.

\section{A formação e o perfil do professor nos objetivos do Pibid, MPs e PNEM}

Para a análise a ser desenvolvida neste tópico, tomamos como base a concepção de que a profissão docente se constitui por meio do diálogo entre elementos teóricos e aqueles advindos das experiências práticas. Nesse sentido, as políticas formativas integram a constituição desse conjunto amplo de conhecimentos e saberes que o professor sustenta sobre a própria profissão, uma vez que, nas suas diferentes proposições, visam inserir o professor em contextos de aprendizagens teóricopráticos. Por isso, é fundamental dar atenção às concepções que norteiam tais políticas. 
Conforme já dito, o Pibid objetiva alcançar o futuro professor na formação inicial. Dada a sua abrangência e proporção dos investimentos, trata-se de um programa que formará um número importante de uma geração de professores que ministrarão e/ou ministram aulas em todos os níveis da educação básica. No Regulamento do Pibid constam os seguintes objetivos:

Art. $4^{\circ}[\ldots]$

I incentivar a formação de docentes em nível superior para a educação básica;

II contribuir para a valorização do magistério;

III elevar a qualidade da formação inicial de professores nos cursos de licenciatura, promovendo a integração entre educação superior e educação básica;

IV inserir os licenciandos no cotidiano de escolas da rede pública de educação, proporcionando-lhes oportunidades de criação e participação em experiências metodológicas, tecnológicas e práticas docentes de caráter inovador e interdisciplinar que busquem a superação de problemas identificados no processo de ensino e aprendizagem;

V incentivar escolas públicas de educação básica, mobilizando seus professores como coformadores dos futuros docentes e tornando-as protagonistas nos processos de formação inicial para o magistério;

VI contribuir para a articulação entre teoria e prática necessárias à formação dos docentes, elevando a qualidade das ações acadêmicas nos cursos de licenciatura;

VII contribuir para que os estudantes de licenciatura se insiram na cultura escolar do magistério, por meio da apropriação e da reflexão sobre instrumentos, saberes e peculiaridades do trabalho docente.

VIII articular-se com os programas de formação inicial e continuada de professores da educação básica, de forma a contribuir com a criação ou com o fortalecimento de grupos de pesquisa que potencialize a produção de conhecimento sobre ensinar e aprender na Educação Básica;

IX comprometer-se com a melhoria da aprendizagem dos estudantes nas escolas onde os projetos institucionais são desenvolvidos. (Brasil. Capes, 2016, anexo 1).

O inciso I dialoga com o previsto no art. 62 da LDB: possibilitar que o professor tenha formação em nível superior; enquanto que o inciso II, na mesma linha, pretende a valorização do magistério. Cabe destacar que, ao longo do texto, essa última questão não apresenta maiores definições acerca do que seria e de como se daria essa valorização. Ao leitor fica subentendido que o conjunto de ações formativas propostas nos objetivos levaria a essa valorização. As questões relacionadas às condições de trabalho e sua precariedade e à valorização profissional e salarial - que, inclusive, são as que mais afastam o futuro professor da docência -, não são abordadas nem postas como condição fundamental a ser enfocada durante essa formação. Com isso, cria-se a ideia de que a melhoria do trabalho docente depende somente da qualidade da formação do professor e, consequentemente, das práticas e conhecimentos que poderá manejar.

Os incisos III, VI e VII tocam numa questão histórica: a necessidade de fortalecer a relação entre universidade e escola e de superar a dicotomia entre 
teoria e prática vigente durante a formação na universidade e também durante o exercício docente. De diferentes perspectivas, esses três incisos apontam para aquilo que Imbernón (2000) chamou de um discurso paradoxal, contraditório porque postula que o nível acadêmico é importante para essa formação e, ao mesmo tempo, aponta as suas fragilidades, dentre as quais se destaca a não superação da concepção que dá maior valor aos conhecimentos teóricos, específicos, em detrimentos dos conhecimentos práticos. Nesse sentido, a exigência prevista nos objetivos do programa para que haja equilíbrio e acomodação entre formação teórica e prática instala o dilema da formação culta versus a formação para a prática. Isso ocorre porque, por meio das ações do Pibid, deve-se, ao mesmo tempo, formar um professor culto - com capacidade para pensar as práticas de ensino considerando conhecimentos filosóficos e científicos -, e um professor prático/técnico - que, a partir da experiência de formação no programa, seja "capaz de entrar numa sala de aula e, aplicando regras relativas à conduta e aos conhecimentos a serem transmitidos, seja capaz de se desempenhar a contento diante dos alunos" (Saviani, 2011, p. 13).

Os incisos V e VII entendem a escola como locus da formação e o professor que lá está como coformador dos futuros professores. Especificamente, o inciso V contrapõe-se a uma prática muito denunciada no âmbito da realização dos estágios supervisionados: a transformação da escola em mero figurante dessa formação, uma vez que dela é demandada a oferta de espaço e de supervisor do estágio. No reverso do discurso de defesa da necessidade de fazê-la protagonista, está o que a coloca como não protagonista desse processo. Nessa perspectiva, o documento traz também a afirmação implícita (VII) de que a docência se constitui como prática social a partir do entrecruzamento de conhecimento teórico e de saberes da prática. A ação docente que possibilita ao professor ocupar a posição de um profissional transformador de seus alunos constitui-se com base nas apropriações e reflexões sobre os modos de confecção e funcionamento dos instrumentos didático-pedagógicos; admite-se também que há saberes e peculiaridades nessa profissão que são somente acessíveis no contexto escolar.

O inciso VIII aborda duas questões distintas. A primeira diz respeito à ideia de combater a fragmentação, dispersão e descontinuidade existentes nas IES, em decorrência (acredita-se) da diversificação dos modelos de funcionamento dessas instituições, e nas instâncias superiores propositoras das políticas de formação. A segunda parte enfoca a criação de grupos de pesquisa, reafirmando assim a importância da formação acadêmica acrescida de outra demanda: a produção de conhecimento sobre o que significa ensinar e aprender na educação básica. Nessa perspectiva, o professor que está na escola é colocado na posição de quem tem o que dizer sobre a formação que se realiza nas IES. Um sujeito de conhecimento e não somente da prática.

Por fim, o inciso IX traz a exigência de que as IES se comprometam também com a melhoria da aprendizagem (e não só do ensino) dos alunos da educação básica. Isso traz, para o âmbito da formação, a proposição de que a aprendizagem do aluno que está na escola é também responsabilidade das IES. Nestas é muito presente a visão de que o aprendizado do aluno da educação básica é responsabilidade 
da escola, que, inclusive, é muito criticada por não realizar essa tarefa a contento. Nesse sentido, o comprometimento é indireto e precisa ocorrer na efetivação da formação de um professor capaz de mudar a qualidade da aprendizagem na escola. Um professor transformador da educação escolar hoje realizada.

Por sua vez, os mestrados profissionais, tendo como foco o professor em atuação, buscam oferecer uma formação mais completa do que os cursos de especialização (e os que ficaram conhecidos nos documentos oficiais como sendo de aperfeiçoamento), ancorada em conhecimentos científicos que permitam ao professor atuar no mercado de trabalho. Assim, o art. $3^{\circ}$ da Portaria MEC $n^{\circ}$ 17/2009, que retoma a Portaria MEC $n^{\circ} 7 / 2009$, define os MPs como cursos de pós-graduação stricto sensu, e o art. $4^{\circ}$ explicita os seus objetivos:

Art. $3^{\circ} \mathrm{O}$ mestrado profissional é definido como modalidade de formação pós-graduada stricto sensu [...].

Art. $4^{\circ}$ São objetivos do mestrado profissional:

I capacitar profissionais para o exercício da prática profissional avançada e transformadora de procedimentos, visando atender demandas sociais, organizacionais ou profissionais e do mercado de trabalho;

II transferir conhecimento para a sociedade, atendendo demandas específicas e de arranjos produtivos com vistas ao desenvolvimento nacional, regional ou local;

III promover a articulação integrada da formação profissional com entidades demandantes de naturezas diversas, visando melhorar a eficácia e a eficiência das organizações públicas e privadas por meio da solução de problemas e geração e aplicação de processos de inovação apropriados;

IV contribuir para agregar competitividade e aumentar a produtividade em empresas, organizações públicas e privadas. (Brasil. MEC, 2009).

Cabe destacar que a semântica do termo "mestrado profissional", em contraponto ao termo "mestrado acadêmico", estabelece uma diferenciação que, de fato, traz na sua gênese a crítica à formação docente que ocorre nos modelos vigentes nas IES, por ser muito teórica e afastada das demandas da escola e da sociedade. O inciso I dá visibilidade a essa diferenciação ao definir que o objetivo deve ser a capacitação para a prática profissional avançada e transformadora de procedimentos (não de humanos), o que remete às exigências dos organismos internacionais que definem que as políticas públicas educacionais devem ter como meta responder às demandas de um mercado de trabalho competitivo e globalizado (Tommasi; Warde; Haddad, 2009). Isso inclui a exigência de uma formação de professor universalizada/profissionalizada, logo técnica. Se os objetivos do Pibid apresentam a prevalência da concepção de formação de um professor culto, os dos MPs voltam-se para a técnica; daí, a necessidade de ser avançada, transformadora de procedimentos para que atenda às demandas sociais, organizacionais ou profissionais do mercado de trabalho. O professor a ser formado por essa perspectiva - inciso II -, precisa assumir a posição do técnico capaz de transferir (não construir) conhecimento de modo a atender às demandas do campo produtivo relacionadas aos contextos nacionais, regionais e locais. 
Os incisos III e IV trazem exigências que são do campo empresarial e econômico: melhoria da eficácia e eficiência, solução de problemas, geração de processos inovadores, aumento de produtividade e competitividade. Esses termos remetem às altas exigências do mercado econômico contemporâneo e, consequentemente, do trabalho como força produtiva do capital empresarial. Quando traduzidos para o campo da educação e da formação, dadas as especificidades e precariedades que hoje permeiam a prática profissional dos professores, tais exigências tendem a ser tomadas como simples e, rapidamente, são assimiladas como modelos a serem seguidos. Além disso, essas características tecnicistas podem levar o professor a ter dificuldades para compreender os ritmos das escolas e para incorporar essas exigências no contexto escolar, sobretudo na escola pública. Ao serem usadas como eixos para estruturar os mestrados profissionais voltados à formação docente, tais exigências deixam de considerar a realidade da profissão docente no que diz respeito às condições de trabalho. Inovação, competitividade e produtividade pressupõem acesso às tecnologias e conhecimentos atuais, tal como se dá no contexto empresarial, algo ainda não disponível na e para a maioria das escolas básicas brasileiras.

Os objetivos postos pela Capes - como diretrizes para concepção, organização e execução dos MPs - são constitutivos e definidores do modo como essa formação tem sido trabalhada nas IES. Ou seja, os MPs se configuram como uma nova trajetória de formação não mais centrada na dimensão acadêmica e sim na dimensão profissional. Com base nessas diretrizes legais, dá-se a criação dos inúmeros programas de MPs (com funcionamento em rede ou não) para formar professores para a educação básica em diferentes áreas do conhecimento. As versões em rede desses programas, que aprofundam o caráter neoliberal e racionalista presentes nas políticas formativas, apresentam as seguintes características organizativas: objetivos e currículo vigentes em âmbito nacional, orientações teórico-metodológicas comuns, modelos para a produção dos trabalhos de conclusão de curso e, em muitos, bibliografia das disciplinas unificada. Esse processo incide, principalmente, na relação que o professor estabelece com o conhecimento e com os próprios saberes da prática, uma vez que provoca a homogeneização dos modos de olhar, questionar e buscar respostas para os problemas que se apresentam como objeto de estudo e orientam a busca de soluções.

No que diz respeito ao PNEM, nos documentos que orientam as ações de formação continuada de professores e coordenadores do ensino médio para os anos de 2013 e 2014, afirma-se que, nos fundamentos e objetivos desse programa, está a busca por uma escola que ofereça, no decorrer do ensino médio, uma formação integral que possibilite o desenvolvimento do ser humano na sua totalidade, não cindido pela divisão social advinda da ideia de uma formação para o trabalho. A formação escolar é concebida, portanto, como meio de emancipação com vistas às leituras de mundo e à participação dos bens sociais, culturais e produtivos. Tal concepção, expressa no texto orientador do Pacto, fundamenta-se nas Diretrizes Curriculares para o Ensino Médio (DCNEM) na medida em que concebe o trabalho docente englobando ciência, cultura e novas tecnologias, o que implica considerar, 
no processo formativo, as dimensões da ação humana, o aspecto educativo do trabalho, a pesquisa como eixo fundamental da ação pedagógica e, principalmente, os direitos humanos como princípio central da prática educativa (Brasil. MEC, 2014). Esses princípios expressos nas DCNEM, e tomados como referenciais pelo PNEM, colocam-se na perspectiva de superar a dualidade que, historicamente, marca o ensino médio no Brasil - de um lado, ensino propedêutico para as classes favorecidas com perspectiva de continuação dos estudos, e, de outro, ensino técnico profissionalizante para os filhos da classe trabalhadora. A concepção norteadora desses documentos é a da formação humana integral, que não se coaduna com a que toma a formação escolar como preparação para o trabalho a partir do uso dos conhecimentos científico-tecnológicos.

Para tanto, defende-se que a formação do professor precisa ser pensada a partir de múltiplos espaços e propostas, que podem ser concretizados na educação formal, tais como nos cursos de licenciaturas e nos espaços de formação continuada. A partir disso, o documento orientador das ações de formação continuada de professores e coordenadores pedagógicos do ensino médio em 2014 traz as seguintes afirmações:

Objetivo geral: Formar em nível de aperfeiçoamento ou extensão todos os professores e coordenadores pedagógicos que atuam no Ensino Médio com vistas à valorização da formação do professor e dos profissionais da Educação a partir do diálogo entre conhecimentos teóricos e experiências docentes e de gestão pedagógica.

Descrição do curso: O curso privilegia a articulação entre a teoria e a prática no processo de formação docente, fundado no domínio de conhecimentos científicos e didáticos. Considera a escola como lócus de formação continuada e (re)construção coletiva do projeto político-pedagógico em suas articulações com as concepções de juventude e direito à qualidade social da educação.

Metodologia: A proposta do curso compreende o professor como um sujeito epistêmico, que elabora e produz conhecimentos com base na compreensão da realidade e nas possibilidades de transformação da sociedade [...]. (Brasil. MEC, 2014, p. 5).

O objetivo "formar (...) a partir do diálogo entre conhecimentos teóricos e experiências docentes" é detalhado no item seguinte: "o curso privilegia a articulação entre a teoria e a prática no processo de formação docente, fundado no domínio de conhecimentos científicos e didáticos". Logo, o professor é concebido como um "sujeito epistêmico, que elabora e produz conhecimentos com base na compreensão e nas possibilidades de transformação da sociedade". Tais fundamentos permitem interpretar que o Pacto pretende uma formação continuada que coloca o professor na posição de sujeito portador de saberes práticos e que, a partir disso, pode promover discussões teórico-práticas com vistas à construção de respostas de caráter científico para os problemas pedagógicos contextuais que se apresentam na e para a escola.

Dito de outro modo, por meio das práticas formativas, possibilitará as condições necessárias para refletir sobre as reais necessidades da escola e, à luz dos seus conhecimentos teóricos, poderá construir respostas para os problemas que 
se apresentam no decorrer do trabalho docente. Para tanto, os conhecimentos teóricos advindos desse processo de formação precisam se desdobrar de modo a se transformarem e/ou dialogarem com os conhecimentos relacionados com as questões mais amplas, tais como educação, economia, política e sociedade e suas relações com os aspectos sociocognitivos da aprendizagem e do desenvolvimento humano. Como sujeito epistêmico, esse docente é um sujeito ético, com responsabilidades sociais, individuais e investigativas - aqui entra também o papel da pesquisa no avanço na compreensão do seu próprio trabalho.

As características do curso de formação do Pacto, conforme apontadas acima, evidenciam a estratégia da formação em serviço tendo, talvez, dois objetivos principais:

a) ampliar o alcance do programa ao realizar a formação na escola (usando a hora atividade);

b) preparar o maior número possível de professores e coordenadores pedagógicos do ensino médio para a reforma que se pretende para esse nível de ensino - o redesenho curricular a partir de áreas do conhecimento.

Nessa perspectiva, "a formação contínua tende a articular-se em primeira linha com os objetivos do sistema, nomeadamente com o desenvolvimento da reforma" (Nóvoa, 1992, p. 9). Desse modo, o desenvolvimento profissional dos professores e o desenvolvimento organizacional da escola seriam consequências do processo desencadeado pelo programa.

\section{Considerações finais}

No que diz respeito às três perguntas que nortearam a escrita deste artigo, é possível responder que a formação inicial e continuada no Pibid e no PNEM são concebidas, com maior ou menor ênfase, objetivando a constituição do professor como um sujeito culto, logo conhecedor e produtor de conhecimentos teóricos considerados fundamentais à compreensão e transformação da sua prática profissional. Nesse sentido, a formação acadêmica é criticada naquilo que não dialoga com a escola, mas é posta como necessária às mudanças que as políticas educacionais visam promover na educação básica. Pleiteia-se nesses dois programas a mudança na forma de efetivação.

Já os MPs reivindicam uma formação técnica, voltada para as exigências das economias e, consequentemente, do mercado de trabalho globalizado. Concebidas à luz das exigências de profissionalização das áreas administrativas e exatas, dentre outras, as diretrizes da Capes que orientam a criação de MPs se ancoram num conjunto de discursos que coloca a formação oferecida pelas IES em xeque.

A relação entre condições de trabalho, valorização do magistério, carreira e salários e melhoria da qualidade da educação básica não é abordada no documento do Pibid, embora, conforme assinalado nas análises, pode-se partir do princípio que o conjunto de ações demandadas pelo programa criaria as condições para que 
o professor se engajasse também em políticas que visam a mudanças nesses aspectos. O PNEM, ao trazer nas suas diretrizes a concepção de que as mudanças educacionais prescindem de compreensão e engajamento e, principalmente, que o trabalho docente engloba um empenho na formação e desenvolvimento humano em todos os seus aspectos, coloca de forma contundente a necessidade de que sejam garantidas as condições de trabalho e a valorização do profissional docente. As diretrizes dos MPs, pelo que é próprio dos seus fundamentos, não sinalizam a necessidade de abordar tais questões - ao contrário, apontam para uma perspectiva que tende a reforçar a precarização humana nos contextos profissionais a serviço da produtividade, dos resultados e de seus avanços.

No que diz respeito ao diálogo com o atual PNE, os três programas apresentam objetivos que corroboram com as metas 15, 16 e 17 do plano. No caso do PNEM, também com a meta 18. Assim, tendo em vista o proposto no PNE, tais programas, considerando a importância do processo educativo para a formação das novas gerações e as características exigidas desse profissional, representam um passo relevante no sentido da implementação de políticas de formação atreladas também às de valorização da carreira para além do ofício. Porém, tendo em vista as metas do PNE, faz-se necessária a inclusão, nessas políticas formativas, de diretrizes que não só formem os profissionais docentes com uma compreensão/concepção de que a melhoria da educação passa pela melhoria das suas condições de trabalho, salários e valorização do magistério, mas também que as atrelem a ações governamentais que avancem na criação de condições e possibilidades de reconhecimento e respeito condizentes com o papel social atribuído a esse profissional, garantindo o desenvolvimento de recursos humanos para atender às demandas sociais e econômicas (Gatti; Barretto; André, 2011).

\section{Referências bibliográficas}

AZEVEDO, J. M. L.; AGUIAR, M. Â. A produção do conhecimento sobre a política educacional no Brasil: um olhar a partir da Anped. Educação \& Sociedade, Campinas, v. 22, n. 77, p. 49-70, dez. 2001. Disponível em: <http://www.scielo. br/scielo.php?script=sci_arttext\&pid=S0101-73302001000400004 > . Acesso em: 2 mar. 2017.

BRASIL. Constituição (1988). Constituição da República Federativa do Brasil. Texto constitucional promulgado em 5 de outubro de 1988, com as alterações adotadas pelas Emendas Constitucionais n ${ }^{\circ}$ 1/1992 a 56/2007 e pelas Emendas Constitucionais de Revisão no 1 a 6/1994. Brasília: Senado Federal, 2008.

BRASIL. Decreto no 6.755, de 29 de janeiro de 2009. Institui a Política Nacional de Formação de Profissionais do Magistério da Educação Básica, disciplina a atuação da Coordenação de Aperfeiçoamento de Pessoal de Nível Superior CAPES no fomento a programas de formação inicial e continuada, e dá outras providências. Diário Oficial da União, Brasília, DF, 30 jan. 2009. Revogado pelo Decreto no 8.752/2016. 
BRASIL. Decreto n 8.752, de 9 de maio de 2016. Dispõe sobre a Política Nacional de Formação dos Profissionais da Educação Básica. Diário Oficial da União, Brasília, DF, 10 maio 2016.

BRASIL. Lei no 9.394, de 20 de dezembro de 1996. Estabelece as diretrizes e bases da educação nacional. Diário Oficial da União, Brasília, DF, 23 dez. 1996. Disponível em: http://www.planalto.gov.br/ccivil_03/leis/L9394.htm >. Acesso em: 2 mar. 2017.

BRASIL. Conselho Nacional de Educação (CNE). Câmara de Educação Básica (CEB). Parecer CNE/CEB no 5/2011. Diretrizes curriculares nacionais para o ensino médio. Brasília, 2011. Disponível em: < http://portal.mec.gov.br/index. php?option=com_docman\&view $=$ download\&alias $=13448$-diretrizes-curicularesnacionais-2013-pdf\&Itemid=30192 > . Acesso em: 4 mar. 2017.

BRASIL. Conselho Nacional de Educação (CNE). Câmara de Educação Básica (CEB). Resolução $n^{\circ}$ 2, de 30 de janeiro de 2012. Define diretrizes curriculares nacionais para o ensino médio. Brasília, 2012. Disponível em: < http://pactoensinomedio. mec.gov.br/images/pdf/resolucao_ceb_002_30012012.pdf>.

BRASIL. Coordenação de Aperfeiçoamento de Pessoal de Nível Superior (Capes). Portaria Normativa Capes no 122, de 16 de setembro de 2009. Dispõe sobre o PIBID - Programa Institucional de Bolsa de Iniciação à Docência, no âmbito da CAPES. Disponível em: < http://www.capes.gov.br/images/stories/download/bolsas/ PortariaNormativa122_PIBID.pdf>. Acesso em: 3 mar. 2017.

BRASIL. Coordenação de Aperfeiçoamento de Pessoal de Nível Superior (Capes). Diretoria de Formação de Professores da Educação Básica (DEB). Relatório de gestão Prodocência. Brasília, 2013. Disponível em: < http://www.capes.gov.br/ images/stories/download/bolsas/1892014-relatorio-PRODOCENCIA.pdf> . Acesso em: 2 mar. 2017.

BRASIL. Coordenação de Aperfeiçoamento de Pessoal de Nível Superior (Capes). Portaria $n^{\circ} 46$, de 11 de abril de 2016. Aprova o regulamento do Programa Institucional de Bolsa de Iniciação à Docência - Pibid. 2016. Disponível em: $<$ https://www.capes.gov.br/images/stories/download/legislacao/15042016Portaria-46-Regulamento-PIBID-completa.pdf $>$.

BRASIL. Instituto Nacional de Estudos e Pesquisas Educacionais Anísio Teixeira (Inep). Plano Nacional de Educação PNE 2014-2024: linha de base. Brasília: Inep, 2015. Disponível em: <http://portal.inep.gov.br/ documents/186968/485745/Plano+Nacional+de+Educa\%C3\%A7\%C3\% A3o + PNE+2014-2024 + + Linha + de + Base/c2dd0faa-7227-40ee-a52012c6fc77700f?version=1.1 >. Acesso em: 3 mar. 2017.

BRASIL. Ministério da Educação (MEC). Portaria normativa nº 38, de 12 de dezembro de 2007. Dispõe sobre o Programa de Bolsa Institucional de Iniciação à Docência - PIBID. Diário Oficial da União, Brasília, DF, 13 dez. 2007. 
BRASIL. Ministério da Educação (MEC). Portaria normativa nº 7, de 22 de junho de 2009. Dispõe sobre o mestrado profissional no âmbito da Fundação Coordenação de Aperfeiçoamento de Pessoal de Nível Superior - Capes. Diário Oficial da União, Brasília, DF, 23 jun. 2009.

BRASIL. Ministério da Educação (MEC). Portaria normativa no 17, de 28 de dezembro de 2009. Dispõe sobre o mestrado profissional no âmbito da Fundação Coordenação de Aperfeiçoamento de Pessoal de Nível Superior CAPES. Diário Oficial da União, Brasília, DF, 29 dez. 2009.

BRASIL. Ministério da Educação (MEC). Portaria n 1.140, de 22 de novembro de 2013. Institui o Pacto pelo Fortalecimento do Ensino Médio e define suas diretrizes gerais, forma, condições e critérios para a concessão de bolsas de estudo e pesquisa no âmbito do ensino médio público, nas redes estaduais e distrital de educação. Diário Oficial da União, Brasília, DF, 9 dez. 2013.

BRASIL. Ministério da Educação (MEC). Secretaria de Educação Básica (SEB). Pacto Nacional pelo Fortalecimento do Ensino Médio: documento orientador das ações de formação continuada de professores e coordenadores pedagógicos do Ensino Médio em 2014. [Brasília], 2014. Disponível em: $<$ http://pactoensinomedio.mec.gov.br/images/pdf/documento_orientador.pdf>. Acesso em: 3 jan. 2017.

BRASIL. Ministério da Educação (MEC). Secretaria de Educação Básica (SEB). Pacto Nacional pelo Ensino Médio: formação de professores do ensino médio: documento orientador preliminar. Brasília, 2013. Disponível em: < http:// www.observatoriodoensinomedio.ufpr.br/wp-content/uploads/2014/03/pnemproposta-de-formac3a7c3a3o-continuada-de-professores.pdf $>$. Acesso em: 3 mar. 2017

BRZEZINSKI, I. (Org.). LDB dez anos depois: reinterpretação sob diversos olhares. 2. ed. São Paulo: Cortez, 2008.

FREITAS, H. C. L. A (nova) política de formação de professores: a prioridade postergada. Educação \& Sociedade, Campinas, v. 28, n. 100 - Especial, p. 1203-1230, out. 2007. Disponível em: < http://www.scielo.br/pdf/es/ v28n100/a2628100>. Acesso em: 31 dez. 2016.

FREITAS, H. C. L. Neotecnicismo e formação do educador. In: ALVES, N. (Org.). Formação de professores: pensar e fazer. 11. ed. São Paulo: Cortez, 2011. GATTI, B. A. Análise das políticas públicas para formação continuada no Brasil, na última década. Revista Brasileira de Educação, Rio de Janeiro, v. 13, n. 37, p. 57-70, jan./abr. 2008. Disponível em: < http://www.scielo.br/ pdf/rbedu/v13n37/06.pdf>. Acesso em: 2 mar. 17.

GATTI, B. A.; BARRETTO, E. S. S.; ANDRÉ, M. E. D. A. Políticas docentes no Brasil: um estado da arte. Brasília: Unesco, 2011. Disponível em: <http:// unesdoc.unesco.org/images/0021/002121/212183por.pdf>. Acesso em: 30 dez. 2016.

IMBERNÓN, F. Formação docente e profissional. 3. ed. São Paulo: Cortez, 2000. 
MAZZEU, L. T. A política de formação docente no Brasil: fundamentos teóricos e metodológicos. In: REUNIÃO ANUAL DA ANPED, 32., 2009, Caxambu. Anais... Caxambu: Anped, 2009. Disponível em: < http://32reuniao.anped.org.br/arquivos/ trabalhos/GT05-5789-Int.pdf>. Acesso em: 31 dez. 2016.

MONTANDON, M. I. Políticas públicas para a formação de professores no Brasil: os programas Pibid e Prodocência. Revista da ABEM, Londrina, v. 20, n. 28,

p. 47-60, 2012. Disponível em: <http://www.abemeducacaomusical.com.br/ revistas/revistaabem/index.php/revistaabem/article/viewFile/103/86>. Acesso em: 2 mar. 2017.

NÓVOA, A. Formação de professores e profissão docente. In: NÓVOA, A. (org.). Os professores e sua formação. Lisboa: Publicações Dom Quixote, 1992.

SAVIANI, D. A nova lei da educação: trajetória, limites e perspectivas. Campinas: Autores Associados, 1997.

SAVIANI, D. Formação de professores no Brasil: dilemas e perspectivas. Poíesis Pedagógica, Catalão, v. 9, n. 1, p. 7-19, jan./jun. 2011. Disponível em: <https://www.revistas.ufg.br/poiesis/article/view/15667>. Acesso em: 5 jan. 2017.

TOMMASI, L.; WARDE, M. J; HADDAD, S. O Banco Mundial e as políticas educacionais. São Paulo: Cortez, 2009.

WEBER, S. O Plano Nacional de Educação Docente: confluências do debate nacional. Cadernos Cedes, Campinas, v. 35, n. 97, p. 495-515, set./dez. 2015. Disponível em: < http://www.scielo.br/pdf/ccedes/v35n97/1678-7110ccedes-35-97-00495.pdf>. Acesso em 5 jan. 2017.

Marinalva Vieira Barbosa, doutora em Linguística pela Universidade Estadual de Campinas (Unicamp), com estágio no Laboratório Interactions, Corpus, Apprentissages, Représentations (ICAR), ligado à Université Lyon 2 e à Ecole Normale Superieure de Sciences Humaines et Lettres de Lyon, e pós-doutorado na Faculdade de Educação da Unicamp, é professora adjunta do Departamento de Linguística e Língua Portuguesa da Universidade Federal do Triângulo Mineiro (UFTM). Foi coordenadora institucional do Pibid no período de julho de 2011 a agosto de 2015, docente permanente do Programa de Mestrado em Educação e do Profletras da UFTM.

marinalva.barbosa@uftm.edu.br

Natália Aparecida Morato Fernandes, doutora em Sociologia, é professora do Departamento de Filosofia e Ciências Sociais da Universidade Federal do Triângulo Mineiro (UFTM). Atua nos cursos de Licenciatura e Serviço Social e realiza atividades de pesquisa e extensão sobre as temáticas: políticas educacionais; formação de professores; práticas de ensino interdisciplinares; mídia, educação e novas cidadanias.

natmorato@gmail.com 